\title{
NEUROPHARMACOLOGICAL SCREENING OF ZAMZAM WATER REVEALED ITS ANXIOLYTIC AND ANTIDEPRESSANT EFFECT
}

\author{
Rahila Najam ${ }^{1}$, Bushra Riaz ${ }^{{ }^{*}}$ \\ ${ }^{1}$ Department of Pharmacology, Faculty of Pharmacy, University of Karachi, Karachi.
}

\section{ABSTRACT}

Introduction: Zamzam water is utilized by Muslims either medicinally or religiously.Zamzam water has therapeutic potential and it can be further assessed for its curative effects.

Material and method: The purpose of this study is to check the pharmacological and therapeutic action of Zamzam. For this purposecollection of zamzam was done from Mecca, Saudiarabia and neuropharmacological screening of zamzam water was done.Among CNS screening test, cage crossing test, open field test, stationary rod test, head dip test, light and dark test and forced swim test were performed.

Result: It was analyzed that Zamzam water possess anxiolytic and antidepressant effects. Zamzam water decrease exploration and increase learning and memory.

Keywords: Zamzam water, anxiolytic, antidepressant, exploration.

\section{INTRODUCTION}

Zamzam water is utilized by Muslims either medicinally or religiously. Research by Professor of King Saud University, College of dentistry ${ }^{1}$ dictates that zamzam water contain increased levels of floride as compared to normal water.Floride has been shown to be effective in decreasing the probability of dental carries but excess fluoride can produce gastrointestinal discomfort ${ }^{2}$.Calcium content is also found to be higher in zamzam water as compared to other sources. Ionic calcium is reported as the best form for absorption in bones and teeth. There are controversial reports on the composition of zamzam water taken from different sources and thus the effectiveness of zamzam water for therapy is arguable. The alkalinity of Zamzam water and the existence of trace amounts of lithium may be the reason behind its therapeutic potential ${ }^{3}$. Based on the aforesaid facts therapeutic actions of Zamzam water can be explored. As it contains lithium in its composition it might have therapeutic ability against psychosis and psychological disturbances.The alkaline nature of zamzam water accounts for its ability to neutralize acidity in the stomach and lessens heartburn.Alkalinity makes it potentially capable of reducing oxidative stress. Oxidative stress increases as body becomes acidic

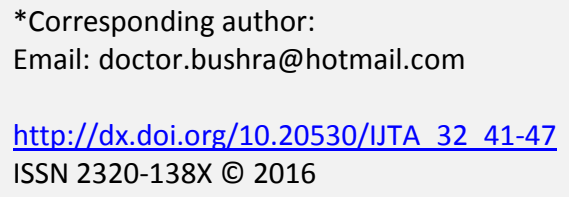

which add toxicity to the body as a result of metabolic exhaust coupled with free radical production.Owing to its antioxidant ability Zamzam water can prevent pathogenesis and complication of many diseases. Zamzam water also showed protection against carbon tetrachloride induced liver toxicity in rats; thereby it is hepatoprotective in nature ${ }^{5}$.

In Zamzam water iodide, sulphate and nitrate are present in large concentration. The concentration of iodide provided by Zamzam water is adequate to fullfill the requirement of iodide for thyroid organ of a body, thus can treat thyroid abnormalities. As it has high percentage of sodium, calcium, magnesium, and many other minerals, Zamzam water has been shown to cure dental carries ${ }^{6}$.Zamzam water also serve as safe substitute of nourishment during labour ${ }^{7}$.

According to a studyZamzam water also possess oncopreventive action ${ }^{8}$. In the light of literature survey it is assumed that zamzam water has therapeutic potential and it can be further assessed for its therapeutic effects. The purpose of this study is to investigate the pharmacological and therapeutic action of zamzam.

\section{MATERIAL AND METHOD}

Before the commencement of study,zamzam water was collected from Mecca, Saudi Arabia in 10litres bottle.

Animals' selection: Albino mice weighing 20-25 gmwere bred at animal house of Department of 
Pharmacology, University of Karachi for CNS screening. The animals were kept under controlled environmental state $23 \pm 2{ }^{\circ} \mathrm{C}$ for 60 days; all animals consumed standard diet made in the laboratory and water adlibitium. Animals were accomodated individually in transparent cages with saw dust covered floor, in a quiet room, under restrained conditions of temperature atleast a week prior to the initiation of the experiments in order to adapt the surrounding. All animals were equally separated into three groups. One group was served as control whereas other group consumed zamzam water adlibitumand standard group received lorazepam in the dose of $0.3 \mathrm{mg} / \mathrm{kg} / \mathrm{d}$ for 60 days. Each group contained 10 animals.

\section{CNS screening test}

\section{Cage crossing test:}

Transparent perspex home cages $(26 \times 26 \times 26 \mathrm{~cm})$ with sawdust covered floor were designed to observe the exploratory activity of mice in acquainted habitat. Mice of each group, one at a time; were placed individually in these cages in order to habituate them with the surroundings. After adaptation period of 5 minutes, number of cage crossing was counted for 10 minutes. The research was done in isolated peaceful room to prevent interruption ${ }^{9}$.

\section{Open field test}

The open field test (OFT) is used to investigate locomotion, exploration and anxiety-related behavior of rodents ${ }^{10}$. The open field apparatus was set up with plywood and comprise of square area 76 $x 76 \mathrm{~cm}$ with walls $42 \mathrm{~cm}$ high. The walls and floor were both white with the floor arena struck in to 25 squares of $15 \mathrm{~cm}$ each. Central squares of equitable size were drawn in the middle of the open field $(15 \mathrm{x}$ $15 \mathrm{~cm}$ ). To perform the experiment mice were taken to the open field apparatus from their home cages. Mice were placed in the centre of the arena facing any side of the open field and its movement was noted for $10 \mathrm{~min}$. After performing the experiment mice were returned to their home cages. To maintain the novelty of the apparatus mice were exposed to the apparatus for $10 \mathrm{~min}$ on two successive days. The number ofcentral square crossing and peripheral square crossing were observed during 10 minutes.

\section{Stationary rod test}

Stationary rod test is one of the behavioral test performed to measure the balance, learning and memory. The mouse was placed on the apparatus of stationary rod comprise of horizontal steel rod $5 / 8$ "in diameter and approximately 2 " in length positioned 18" over the table surface. The mouse was placed on the rod and enforced to walk towards the platform on either end of the rod. Time taken by each mouse to balance itself and travel to the end of rod was observed ${ }^{9}$.

\section{Head Dip Test}

The head dip test is conducted to evaluate anxiety-related behaviours in rodents ${ }^{11}$. The apparatus is made up of a rectangular wooden box $(35 \mathrm{~cm} \times 45 \mathrm{~cm} \times 45 \mathrm{~cm})$ containing four equidistant holes $(2.5 \mathrm{~cm}$ in diameter) on each wall. Each mouse was placed in the centre of the apparatus and allowed to explore the apparatus for $10 \mathrm{~min}$ and the frequency with which mouse dip its head through the holes was noted. After the experiment was performed, hole-board apparatus was cleaned with ethyl alcohol (70\%) for disinfecting and removing any odour left from the previous subject.

\section{Light and dark test:}

The light and dark test also called passive avoidance test was conducted with each mouse where every mouse was placed in enlightened area of 2 compartment light-dark box. Since the dark region of the 2 compartment box has suitable conditions for the rodents because of their nature, they tend to avoid bright area. Therefore the passive avoidance test is used to measure the state of anxiety. Observations as the time spent in light area and number of transitions were noted for each mice during a 10 minutes session ${ }^{12}$.

\section{Forced swim test:}

The apparatus consist of a glass box having height $25 \mathrm{~cm}$ and diameter of $10 \mathrm{~cm}$ containing $8 \mathrm{~cm}$ of water and maintained at $22-24^{\circ} \mathrm{C}$. Mice were separately placed in a glass box and were forcibly made to swim in a confined area that inhibit their chances of escape thus induced a characteristic behavior of depression depicted by their posture of immobility. This deportment indicates a state of desperation. For $5 \mathrm{~min}$ the mice were observed for escape-oriented behaviors such as swimming, jumping, rearing, diving and finally immobility. At every time interval immobility was recorded after observing mice $^{13}$. 


\section{Statistical test:}

For CNS profile (cage crossing, Open Field, Stationary rod, Head Dip, Light and dark test, forced swim test) one-way ANOVA followed by post hoc analysis by Scheffe test was used to evaluate the differences between various means. Asterisk(s) indicate levels of significance i.e. $* P<0.05$ is considered as significant, $* * P<0.001$ as moderate significant and $* * * P<0.0001$ as highly significant.

\section{RESULT}

\section{DISCUSSION}

Neuropharmacological screening of zamzam water revealed that the exploratory and loco motor activities were reduced after administration of zamzam water. The effects of zamzam water on cage crossing signify that activitywas decreased significantly. zamzam water reduced number of cage crossed which shows that it hasinhibitory effect on loco motor activity. The open field activity was decreased initially at 15 and 30 days by zamzam but later on it was augmented at day 60 which might be

Table- 1: Effect of Zamzam on cage crossing activity

\begin{tabular}{lcccc}
\hline \multicolumn{1}{c}{ Groups } & \multicolumn{4}{c}{ number of cage crosses } \\
\cline { 2 - 5 } & day 0 & day15 & day30 & day60 \\
\hline Control & $45 \pm 0.9$ & $44 \pm 2.29$ & $44 \pm 1.776$ & $43 \pm 1.42$ \\
zamzam water & $43 \pm 0.7$ & $38 \pm 4.31^{* * * ! ! !}$ & $28 \pm 4.164^{\#^{* * *} ! !}$ & $30 \pm 8.65^{\#^{* * * ! ! !}}$ \\
lorazepam & $44 \pm 1.0$ & $26 \pm 1.50$ & $13 \pm 1.63$ & $9 \pm 1.48$ \\
\hline
\end{tabular}

Values are mean \pm SD, data analyzed by one way ANOVA, and post hoc analysis by scheffe test suggest $* * *, ! ! ! \mathrm{p}<0.0001$ is considered highly significant as compared to control and standard respetively.

${ }^{\#} \mathrm{p} \leq \mathbf{0 . 0 5}$ is considered significant within zamzam water treated group.

Table- 2: Effect of Zamzam on Central square crosses

\begin{tabular}{lcccc}
\hline \multicolumn{1}{c}{ Groups } & \multicolumn{4}{c}{ number of central square crosses } \\
\cline { 2 - 5 } & day $\mathbf{0}$ & day15 & day30 & day60 \\
\hline Control & $30 \pm 2.0$ & $32 \pm 2.31$ & $31 \pm 2.54$ & $28 \pm 3.62$ \\
zamzam water & $29 \pm 2.1$ & $30 \pm 18.76 !$ & $25 \pm 6.8 !$ & $4 \pm 5.0^{* ! ! !}$ \\
lorazepam & $32 \pm 3.0$ & $20 \pm 3.0$ & $13 \pm 2.01$ & $7 \pm 3.06$ \\
\hline
\end{tabular}

Values are mean \pm SD, data analyzed by one way ANOVA, and post hoc analysis scheffe test suggest $*_{p}<0.05$ is considered significant as compared to control.

! $<<0.05$, !!! $p<0.0001$ is considered significant and highly significant respectively as compared to standard.

Table- 3: Effect of Zamzam on Peripheral square crosses

\begin{tabular}{lcccc}
\hline \multirow{2}{*}{ Groups } & \multicolumn{4}{c}{ number of peripheral square crosses } \\
\cline { 2 - 5 } & day $\mathbf{0}$ & day15 & day30 & day60 \\
\hline Control & $130 \pm 5$ & $133 \pm 7.49$ & $129 \pm 4.58$ & $125 \pm 19$ \\
zamzam water & $126 \pm 14$ & $117 \pm 24.7^{! ! !}$ & $115 \pm 22.04^{! ! !}$ & $131 \pm 38^{! ! !}$ \\
lorazepam & $127 \pm 8$ & $165 \pm 4.97$ & $53 \pm 9.53$ & $15 \pm 1.9$ \\
\hline
\end{tabular}

Values are mean $\pm S D$, data analyzed by one way ANOVA, and post hoc analysis scheffe test suggest !!! $p<0.0001$ is considered highly significant as compared to standard. 
Table- 4: Effect of Zamzam on Head dip activity

\begin{tabular}{lcccc}
\hline \multicolumn{1}{c}{ Groups } & \multicolumn{4}{c}{ number of head dips } \\
\cline { 2 - 5 } & day 0 & day15 & day30 & day60 \\
\hline Control & $30 \pm 1.8$ & $34 \pm 1.47$ & $34 \pm 1.66$ & $36 \pm 1.56$ \\
zamzam water & $35 \pm 1.5$ & $15 \pm 4.73^{* * * ! ! !}$ & $15 \pm 4^{* * * ! !}$ & $13 \pm 3^{* * *}$ \\
lorazepam & $32 \pm 1.4$ & $31 \pm 3.71$ & $22 \pm 2.75$ & $13 \pm 4.5$ \\
\hline
\end{tabular}

Values are mean \pm SD, data analyzed by one way ANOVA, and post hoc analysis scheffe test suggest *** $p<0.0001$ is considered highly significant as compared to control.

!! $p<0.001, ! ! ! p<0.0001$ is considered very significant andhighly significantrespectively as compared to standard.

Table- 5: Effect of Zamzam on Light and Dark model-\% time spent in light compartment

\begin{tabular}{lcccc}
\hline \multirow{2}{*}{ Groups } & \multicolumn{4}{c}{ \% time spent in light compartment } \\
\cline { 2 - 5 } & day 0 & day15 & day30 & day60 \\
\hline Control & $40 \pm 5.3$ & $38 \pm 6.24$ & $41 \pm 2.66$ & $35 \pm 6.51$ \\
zamzam water & $36 \pm 3.6$ & $39 \pm 5.28$ & $42 \pm 10^{! ! !}$ & $46 \pm 1.16^{* * ! ! !}$ \\
lorazepam & $34 \pm 4.11$ & $35 \pm 5.7$ & $7 \pm 3.8$ & $1 \pm 0.15$ \\
\hline
\end{tabular}

Values are mean \pm SD, data analyzed by one way ANOVA, and post hoc analysis scheffe test suggest ${ }^{* *} p<0.001$ is considered very significant as compared to control.

$! ! ! p<0.0001$ is considered highly significant as compared to standard.

Table- 6: Effect of Zamzam on Light and Dark model- number of transitions

\begin{tabular}{lcccc}
\hline \multirow{2}{*}{ Groups } & \multicolumn{4}{c}{ number of transitions } \\
\cline { 2 - 5 } & day 0 & day15 & day30 & day60 \\
\hline Control & $20 \pm 5.3$ & $20 \pm 3.1$ & $18 \pm 3.1$ & $19 \pm 4.2$ \\
zamzam water & $18 \pm 3.6$ & $21 \pm 2.3^{! ! !}$ & $18 \pm 4.1^{! ! !}$ & $22 \pm 1.6^{* ! ! !}$ \\
lorazepam & $17 \pm 4.5$ & $9 \pm 4.6$ & $8 \pm 3.5$ & $7 \pm 2.63$ \\
\hline
\end{tabular}

Values are mean \pm SD, data analyzed by one way ANOVA, and post hoc analysis scheffe test suggest ${ }^{*} \mathrm{p}<0.05$ is considered significant as compared to control.

!!! $p<0.0001$ is considered highly significant as compared to standard.

Table- 7: Effect of Zamzam on Stationary Rod Activity

\begin{tabular}{lcccc}
\hline \multicolumn{1}{c}{ Groups } & \multicolumn{4}{c}{ Time taken to reach the platform } \\
\cline { 2 - 5 } & day $\mathbf{0}$ & day15 & day30 & day60 \\
\hline Control & $15 \pm 1.3$ & $13 \pm 2.21$ & $14 \pm 1.27$ & $12 \pm 1.36$ \\
zamzam water & $16 \pm 1.5$ & $12 \pm 1.59 ! ! !$ & $12 \pm 1.85 ! !$ & $9 \pm 3.01 * ! ! ! \#$ \\
lorazepam & $13 \pm 2.2$ & $22 \pm 1.74$ & $17 \pm 1.81$ & $17 \pm 7$ \\
\hline
\end{tabular}

Values are mean $\pm S D$, data analyzed by one way ANOVA, and post hoc analysis scheffe test suggest ${ }^{*}, \# p<0.05$ is considered significant as compared to control and within zamzam water treated group respectively.

!! $p<0.001$, !!! $p<0.0001$ is considered very significant andhighly significantrespectively as compared to standard. due to the fact that zamzam water reduces anxiety 
Table- 8: Effect of Zamzam on Forced swimming test

\begin{tabular}{lcccc}
\hline \multicolumn{1}{c}{ Groups } & \multicolumn{4}{c}{ struggling time (sec) } \\
\cline { 2 - 5 } & day 0 & day15 & day30 & day60 \\
\hline Control & $90 \pm 1.2$ & $92 \pm 2.28$ & $84 \pm 1.96$ & $86.4 \pm 1.82$ \\
zamzam water & $85 \pm 0.65$ & $72 \pm 3.44 !$ & $119 \pm 8.59 * * * ! \# \# \#$ & $216 \pm 25.6 * * * ! ! ! \# \# \#$ \\
lorazepam & $88 \pm 0.8$ & $132 \pm 70.98$ & $103 \pm 21.6$ & $135 \pm 24.1$ \\
\hline
\end{tabular}

Values are mean $\pm S D$, data analyzed by one way ANOVA, and post hoc analysis scheffe test suggest

${ }^{* * *}, \# \#$ $\not 0.0001$ is considered highly significant as compared to control and within zamzam water treated group respectively.

! $<<0.05$, !!! $p<0.0001$ is considered significant and highly significant respectively as compared to standard.

which would have made animals comfortable to explore open arena.The head dip activity was decreased by zamzam water at all days of observation as compared to control, indicating the decline in investigativeand exploratory activity. The reduction in head dip activity may be associated with the calming and anxiolytic effects of the compound. It is shown that anxiogenic compounds increase the head dip activity and the reverse is true for the anxiolytic compounds ${ }^{14}$. Due to fear and neophobia animal tries to escape on initial exposure to the apparatus ${ }^{14}$.Elevated levels of corticosteroids in adult rats following first exposure to apparatus further confirm stressful condition of animal ${ }^{15}$.If it is assumed that on exposure to apparatus, anxiety develops due to state of fear so decrease in number of dips shows release from anxiety ${ }^{16}$.This resultis in association of our previous result that zamzam water possess anxiolytic effect.

Anxiolytic or anxiogenic effects of drugs are also determined by light and dark test. In this test the response of rodents is observed when exposed to stressors as light. It is based on innate nature of rodents to resist brightly illuminated area. ${ }^{17}$.Research studies have shown that an animal that develops anxiety tends to stay for prolonged period in darker area. It will not prefer to move and explore the white area and transition between two boxes will also be low. On the other hand anxiolytic drugs enhance the number of transitions and the time spent in the light area ${ }^{18}$.The effect of zamzam water on light/dark box activity indicates that the zamzam water has an anxiolytic activity. The percentage of time spent in light box was increased by Zamzam water and number of transitions between light and dark compartment were alsoamplified by zamzam at day 60 which indicates the decrease in fear from bright arena. The anxiolytic effect of zamzam water may be due to the presence of zinc $^{19,1}$ and magnesium $^{1}$ in zamzam water. Zinc plays an important role in relieving anxiety ${ }^{20}$ as it modulates GABA and glutamate neurotransmission which are involved in anxiolytic activity. Zinc is also known to possess antidepressant action ${ }^{21}$.The antidepressantand anxiolytic-like effects of magnesium are due to inhibition of $\mathrm{N}$-methyl-d-aspartate (NMDA) glutamate receptor ${ }^{22}$.

The effect of zamzamwater onstationary rod activity was also observed. The stationary rod activity test is used to assess the effects of drugs on memory and learning. The effect of zamzamwater on stationary rod activity indicates that the zamzam water improve memory as time taken to reach the platform decreased by zamzam. . The possible reason could be the presence of zinc in zamzam water. Zinc deficiency may affect cognitive development by alterations in attention, activity, neuropsychological behavior and motor development ${ }^{23}$.Also as reported by Slutsky, et al (2010) the administration of magnesium can also enhance the learning abilities. $\mathrm{Mg}$ treated rats showed higher density of synaptophysin/synaptobrevin-positive puncta in DG and CA1 subregions of hippocampus and this could be correlated with memory improvement. Increase in brain magnesium enhances both short-term synaptic facilitation and long-term potentiation and improves learning and memory functions ${ }^{24}$.This effect of zamzamwater on stationary rod activity may be attributed to the presence of lithium in zamzam water $^{25}$. Lithium has been shown to decrease the expression of proapoptoticBax and increase the levels of phosphor- GSK3 and $\mathrm{Bcl}-2$. Therefore lithium is considered as the neuroprotector that increased learning and memory ${ }^{26}$. 
Forced swim test is not only an indicator of antidepressant effect of drugs but it is also used as an indicator of depression in rodents ${ }^{18}$ when mice become immobile after period of vigorous activity it represents depressive state ${ }^{19}$.The effect of zamzam water on swimming induced depression was highly noteworthy. The struggling time was increased by zamzam water to a highly significantextent at day 30 and day 60 as compared to control whichsuggests that zamzam water has antidepressant effect. This effect may be due to the presence of zinc $^{1,19}$, magnesium $^{1}$ and lithium ${ }^{24}$ in zamzam water. Lithium is well known for its mood stabilizing effect. It is used in the treatment of depression and bipolar disorders $^{26}$. It produces antidepressant effects by reducing norepinephrine release and by increasing serotonin synthesis ${ }^{27}$. Lithium alsointeracts with nitric oxide (NO) signaling pathway in the central nervous system, which plays a crucial role in the neural plasticity ${ }^{28}$. The NO system could be involved in the antidepressant effect of lithium in the Porsolt forced swimming test in mice ${ }^{28}$.

\section{CONCLUSION}

At the end of study it is concluded that the presence of magnesium, zinc and lithium in zamzam water gives itunique characteristics. Zamzam water possess anxiolytic and antidepressant actions.Zamzam water decrease exploration and increase learning and memory.

\section{REFERENCES}

1. Al ZuhairN, Khounganian R, Comparative study between the chemical composition of potable water and Zamzam water and its effect on tooth structure in Saudi Arabia, Afaq (Arabic) Dental Journal, 2006;11: 36-37.

2. Gessner BD, Beller M, Middaugh JP, Whitford GM. Acute Fluoride Poisoning from a Public Water System. New England Journal of Medicine. 1994 Jan 13;330(2):95-9. Available from: http://dx.doi.org/10.1056/nejm199401133300203

3. Shomar B. Zamzam water: Concentration of trace elements and other characteristics. Chemosphere. 2012 Feb;86(6):600-5. Available from: http://dx.doi.org/10.1016/j.chemosphere.2011.10.02 5.

4. Bamosa A. Zamzam Water Ameliorates Oxidative Stress and Reduces HemoglobinA1c in Type 2 Diabetic Patients. Journal of Diabetes \& Metabolism. 2013;04(03). Available from: http://dx.doi.org/10.4172/2155-6156.1000249.
5. Bamosa A, Amelioration of Severe Carbon Tetrachloride Toxicity by Zamzam Water in Rats, Nutrition \& Food sciences, 2013.

6. Al- Rawi, Al-AlousiJMR, Al- Obaidy NM, Effect of Zamzam Water on the Microhardness of Initial Carious Lesion of Permanent Teeth Enamel (An in vitro study), MDJ, 6(2), 2009.

7. GhaniRMA, Effect of Zamzam water intake during labor on maternal and neonatal outcome: a randomized controlled trial, academic research international, 2(3), 2012.

8. AliAFM, CosemiE,Kamel $\mathrm{S}$, MohammedS,ElhefnawyM,Farid $\mathrm{L}$ and Shaker $\mathrm{S}$, Zamzam water oncopreventive action, IWTC 13, 1527- 1532, 2009.

9. Najam R, pharmacological screening of some bioactive products from marine resources, Dissertation, University of Karachi, 2003.

10. Mandillo S, Tucci V, Holter SM, Meziane H, Banchaabouchi MA, Kallnik M, et al. Reliability, robustness, and reproducibility in mouse behavioral phenotyping: a cross-laboratory study. Physiological Genomics. 2008 Jun 10;34(3):243-55. Available from: http://dx.doi.org/10.1152/physiolgenomics.90207.20 08

11. Yan Clément, Chantal Joubert,Caroline Kopp, Eve M. Lepicard, Patrice Venault, René Misslin, Martine Cadot, and Georges Chapouthier, Anxiety in Mice: A Principal Component Analysis Study, Neural plasticity, 2007.

12. Crawley J, Goodwin FK. Preliminary report of a simple animal behavior model for the anxiolytic effects of benzodiazepines. Pharmacology Biochemistry and Behavior. 1980 Aug;13(2):167-70. Available from: http://dx.doi.org/10.1016/0091-3057(80)90067-2

13. Pechnick RN, Chesnokova VM, Kariagina A, Price S, Bresee CJ, Poland RE. Reduced Immobility in the Forced Swim Test in Mice with a Targeted Deletion of the Leukemia Inhibitory Factor (LIF) Gene. Neuropsychopharmacology. 2004 Jan 8;29(4):770-6. Available from: http://dx.doi.org/10.1038/sj.npp.1300402.

14. Nuzhat S, Rahila N. anxiolytic activity of aloe vera (L) tested in rodents. Pak J Pharmacol., 29(1):7-15, 2012.

15. Renner MJ. "Neglected aspects of exploratory and investigatory behavior." Psycho Biol 1990;18:16-22.

16. Márquez C, Nadal R, Armario A. Influence of reactivity to novelty and anxiety on hypothalamic-pituitaryadrenal and prolactin responses to two different novel environments in adult male rats. Behavioural Brain Research . 2006 Mar;168(1):13-22. Available from: http://dx.doi.org/10.1016/j.bbr.2005.10.004. 
17. Belzung C, Griebel G. Measuring normal and pathological anxiety-like behaviour in mice: a review. Behavioural Brain Research. 2001 Nov;125(1-2):1419. Available from: http://dx.doi.org/10.1016/s01664328(01)00291-1.

18. Bourin $M$, Hascoet $M$. "The mouse light/dark box test" Eur J Pharmacol 2003;28:1-3. 40. Olena V Bogdanova, ShamiKanekar, Kristen ED Anci, Perry $F$ Renshaw. "Factors influencing behavior in Forced swim test." Physiol Behavior 2013;118:227-39.

19. Shomar B. Zamzam water: Concentration of trace elements and other characteristics. Chemosphere. 2012 Feb;86(6):600-5. Available from: http://dx.doi.org/10.1016/j.chemosphere.2011.10.02 5.

20. Partyka A, Jastrzębska-Więsek $M$, Szewczyk $B$, Stachowicz K, Sławińska A, Poleszak E, et al. Anxiolytic-like activity of zinc in rodent tests. Pharmacological Reports. 2011 Jul;63(4):1050-5. Available from: http://dx.doi.org/10.1016/s17341140(11)70621-1.

21. Samardzic J, Savic K, Stefanovic N, Matunovic R, Baltezarevic D, Obradovic $M$, et al. Anxiolytic and antidepressant effect of zinc on rats and its impact on general behavioural parameters. Military Medical and Pharmaceutical Journal of Serbia. 2013;70(4):391-5. Available from: http://dx.doi.org/10.2298/vsp111129036s.

22. Poleszak E, Szewczyk B, Kędzierska E, Wlaź P, Pilc A, Nowak G. Antidepressant- and anxiolytic-like activity of magnesium in mice. Pharmacology Biochemistry and Behavior. 2004 May;78(1):7-12. Available from: http://dx.doi.org/10.1016/j.pbb.2004.01.006.

23. Bhatnagar S, Taneja S. Zinc and cognitive development. British Journal of Nutrition. 2001 May;85(S2):S139. Available from: http://dx.doi.org/10.1079/bjn2000306.

24. Slutsky I, Abumaria N, Wu L-J, Huang C, Zhang L, Li B, et al. Enhancement of Learning and Memory by Elevating Brain Magnesium. Neuron. 2010 Jan;65(2):165-77. Available from: http://dx.doi.org/10.1016/j.neuron.2009.12.026.

25. Osusky K, Edwards E, Hallahan D. Lithium Is a Neuroprotector That Improves Memory and Learning in Preclinical Models of the Irradiated Developing Brain. International Journal of Radiation Oncology*Biology*Physics. 2005 Oct;63:S261. Available from: http://dx.doi.org/10.1016/j.ijrobp.2005.07.446.

26. "Lithium Salts". The American Society of HealthSystem Pharmacists. Retrieved Dec 1, 2015.
27. Brunton, L; Chabner, B; Knollman, B. Goodman and Gilman's The Pharmacological basis of therapeutics (12th ed.). New York: McGraw-Hill Professional.2010.

28. Ghasemi M, Sadeghipour $H$, Mosleh A, Sadeghipour $H R$, Mani AR, Dehpour AR. Nitric oxide involvement in the antidepressant-like effects of acute lithium administration in the mouse forced swimming test. European Neuropsychopharmacology. 2008 May;18(5):323-32. Available from: http://dx.doi.org/10.1016/j.euroneuro.2007.07.011. 